\title{
Predicting Take-All Severity in Second-Year Wheat Using Soil DNA Concentrations of Gaeumannomyces graminis var. tritici Determined with qPCR
}

Sean L. Bithell, The New Zealand Institute for Plant \& Food Research Limited, Private Bag 4704, Christchurch, New Zealand; Alan McKay, South Australian Research and Development Institute (SARDI), GPO Box 397, Adelaide, SA 5001, Australia; Ruth C. Butler, The New Zealand Institute for Plant \& Food Research Limited, Christchurch; Herdina and Kathy Ophel-Keller, SARDI, Adelaide; Diana Hartley, CSIRO Ecosystem Sciences, Black Mountain, ACT 2601, Australia; and Matthew G. Cromey, The New Zealand Institute for Plant \& Food Research Limited, Christchurch

\begin{abstract}
Bithell, S. L., McKay, A., Butler, R. C., Herdina, Ophel-Keller, K., Hartley, D., and Cromey, M. G. 2012. Predicting take-all severity in second-year wheat using soil DNA concentrations of Gaeumannomyces graminis var. tritici determined with qPCR. Plant Dis. 96:443-451.

The lack of accurate detection of Gaeumannomyces graminis var. tritici inoculum in soil has hampered efforts to predict the risk of severe take-all for wheat growers. The current study used a molecular method to quantify soil G. graminis var. tritici concentrations in commercial wheat fields in New Zealand and to compare them with the proportion of crops surpassing the thresholds for visible and moderate to severe take-all over three growing seasons. The study evaluated a soil G. graminis var. tritici DNA-based take-all prediction system developed in Australia, with four take-all risk categories. These categories were found to be useful for predicting disease severity in second wheat but did not clearly separate risk between fields in medium- and

high-risk categories. A sigmoidal relationship was identified between inoculum concentration and the proportion of fields exceeding the two disease thresholds. A logistic response curve was used to further examine this relationship and evaluate the boundaries between take-all risk categories. G. graminis var. tritici boundaries between medium- and high-risk categories were clustered near or within the upper plateau of the relationship. Alternative G. graminis var. tritici boundaries for a three-category system were identified that provided better separation of take-all risk between categories. This information could improve prediction of the risk of severe take-all.
\end{abstract}

The disease take-all, caused by Gaeumannomyces graminis var. tritici and, to a lesser extent, G. graminis var. avenae, is a serious and yield-limiting constraint in wheat $(1,21)$. Presowing management strategies include the use of rotation to nonhost crops, seed treatments if available, and sowing date manipulation (22). No control methods are available for this disease after crop establishment (21); therefore, information on the risk of take-all prior to sowing is important to minimize the risk of losses.

Predicting when a disease will reach an economic threshold is an important application of plant disease epidemiology (11). Most disease-prediction methods are used to predict whether a fungicide application should be applied or not. For instance, a diseaseprediction algorithm for Sclerotinia stem rot in oil seed rape using a risk point sum was described by Twenstrom and Sigvald (35). The decision threshold was determined by the point where the cost of fungicide applications was offset by the increase in yield. Given a long-enough lead time, disease predictions could help growers decide what and when to plant and what cultural practices to apply (11).

Although many models have been developed for aboveground diseases, the use of models for predicting disease or providing support to manage soilborne or root-infecting plant diseases has been very limited (31). For instance, only 2 of 54 studies of predictive models discussed by De Wolf and Isard (11) involved soilborne diseases.

Forecasting take-all of wheat has proved difficult, with efforts focused on previous cropping history, measuring soil inoculum, and weather conditions (20). Given that no effective controls are

Corresponding author: M. Cromey,

E-mail: matthew.cromey@plantandfood.co.nz

Accepted for publication 25 October 2011.

http://dx.doi.org/10.1094/PDIS-05-11-0445

() 2012 The American Phytopathological Society available after sowing and that long-term weather forecasts are not particularly accurate, presowing take-all prediction is likely to be the most practical.

It is known that the amount of initial inoculum of G. graminis var. tritici is important in disease development and that this is determined primarily by cropping history, the severity of disease in the previous crop, and the rate of inoculum decay (21). Disease severity is usually low in the first wheat crop after a nonhost break but can be very high in a following (second) wheat crop (9). In the absence of direct methods, soil bioassays, where wheat seedlings are grown in soil samples, have been traditionally used to estimate inoculum in the field (20). Long-term data from the United Kingdom suggest that, if plants in a postharvest soil bioassay have $20 \%$ of their roots infected, then the risk of take-all patches in the subsequent crop is high (21).

Strong seasonal effects on the severity of take-all in second-year wheats have previously been reported (36), and the phrase "take-all years" is used to describe years where aboveground symptoms of the disease are widespread compared with years where the symptoms are minor or rare (21). Complex interactions between climatic factors have been shown to affect take-all epidemics, although soil moisture appears to be more important than temperature $(32,34)$. Roget (31) described a model to predict the development of takeall for winter-dominant rainfall regions of southern Australia with annual rainfall $<450 \mathrm{~mm}$. The model is based on quantified soil $G$. graminis var. tritici, with other environmental or management factors acting to increase or decrease the likelihood of disease. Rainfall (during either the growing season or the non-crop period) was the key environmental driver. Therefore, presowing predictions of take-all risk will need to take into account the influence of environment during the growing season on disease risk.

Development of a quantitative DNA assay for G. graminis var. tritici plus G. graminis var. avenae (tritici/avenae) and a separate assay for G. graminis var. avenae provides a means to directly quantify the inoculum of these pathogens in soil samples. These assays along with others are being used by a commercial service to assist farmers in planning their cropping program to minimize 
losses from soilborne diseases (28). The assays are used to quantify DNA from soil samples collected before seeding, to identify which soilborne pathogens pose the greatest risk if a cereal crop were to be established. Four risk categories are used: below detection limit (BDL), low, medium, and high $(<5,5$ to $<130,130$ to $<325$, and $325+$ picograms, respectively, of G. graminis var. tritici DNA per gram of soil) risk of take-all.

The present study sought to evaluate DNA-based quantification of G. graminis var. tritici for take-all risk prediction in New Zealand, where wheat is a high-input crop and cropping practices, grain yields, rainfall and irrigation, and temperatures bear greater similarity to areas of Europe than to South and Western Australia $(8,9,23,28,29)$. Commercial wheat fields were used in this study to evaluate the Australian set of take-all risk categories. The probability (or risk) of take-all exceeding an economic threshold may be more useful for prediction purposes than the relationship between inoculum and disease itself. Such risk predictions can be assessed and then modified when new information is available. Therefore, the proportion of fields exceeding two selected severity thresholds in each category was determined. Data were used to further examine the G. graminis var. tritici concentration-take-all risk relationship, and a logistic response curve was developed to model the data in order to optimize take-all risk prediction. Optimized risk prediction categories were then reevaluated and validated using two further years of data.

\section{Materials and Methods}

Assessment of $G$. graminis var. tritici concentrations in soil. Soil samples were collected from 246 commercial wheat fields over three growing seasons (2003-04, 2004-05, and 2005-06). The terminology of first, second, and third wheat is used to describe the number of consecutive wheat crops following a noncereal break crop (2). The 246 fields included 95 first, 117 second, and 34 third wheats, with the remaining fields being fourth or higher wheats. Included in the 117 second wheats were 15 wheat crops that followed a first barley and two that followed a first triticale. Although these are technically second host cereals, they were included because all are susceptible or moderately susceptible host cereals.

Soil samples were taken from late February to April (autumn) in 2003,2004 , and 2005. In each field, two soil cores (0 to $10 \mathrm{~cm}$ in depth, $10 \mathrm{~mm}$ in diameter) were taken at each of 25 positions along a W pattern (within an area of approximately 0.65 ha), with approximately $10 \mathrm{~m}$ between each position. Where previous crop stubble was standing, one core was taken from between stubble rows (standard row spacing is $150 \mathrm{~mm}$ ) and one from within a stubble row at each position. Location maps and a global positioning system (Garmin GPS76) were used to locate the sample area in each field. Following collection, the samples (approximately 500 g) were placed in a glasshouse (approximately $25^{\circ} \mathrm{C}$ ) for $48 \mathrm{~h}$, which reduced the moisture content to within the range of 2 to $5 \%$. The samples were then oven dried for a further $48 \mathrm{~h}$ at $40^{\circ} \mathrm{C}$ prior to being placed in plastic bags and frozen at $-20^{\circ} \mathrm{C}$ for 2 weeks. The samples were then sent to the laboratory of the South Australian Research and Development Institute (SARDI), Adelaide, Australia, for DNA analysis.

DNA of G. graminis var. avenae and tritici/avenae were quantified by TaqMan MGB real-time polymerase chain reaction (PCR). The primers and probes were designed based on internal transcribed spacer (ITS) 1 ribosomal region sequences from local isolates and others available in GenBank (Table 1). The PCR conditions were described in Riley et al. (30). Cycle threshold (Ct) values (the number of PCR cycles when the fluorescence associated with amplified DNA crosses the defined threshold) were converted to picograms of DNA per gram of soil using a reference standard curve made of 10-fold dilutions for DNA at $200 \mathrm{pg}$ to 2 $\mathrm{fg} / \mu \mathrm{l}$ of DNA from G. graminis var. avenae isolate 137T. Specificity of each assay was evaluated using DNA extracted by Herdina et al. (16). DNA of undescribed ectotrophic root infecting fungi on golf turf in Queensland (M. Stirling, Biological Crop Protection, QLD, Australia) were also used (Table 2).

DNA was extracted from soil samples of up to $500 \mathrm{~g}$ dry weight by a purpose-built facility at SARDI that is accredited to extract DNA from local and international soil samples (28).

Take-all assessments. Approximately 100 plants were dug from each field at the early grain-fill stage (December), using GPS to locate the area from which soil had previously been sampled for

Table 2. Specificity testing of the real-time polymerase chain reaction (PCR) assays specific for Gaeumannomyces graminis var. avenae and the G. graminis var. tritici plus G. graminis var. avenae (tritici/avenae) assay

\begin{tabular}{|c|c|c|}
\hline \multirow[b]{2}{*}{ Species, isolate name } & \multicolumn{2}{|c|}{ Ct value threshold $0.1^{\mathrm{a}}$} \\
\hline & G. graminis var. avenae & tritici/avenae \\
\hline G. cylindrosporus & ND & 39.7 \\
\hline G. incrustans & ND & 38.2 \\
\hline \multicolumn{3}{|l|}{ G. graminis var. avenae } \\
\hline $137 \mathrm{~T}$ & 27.5 & 24.6 \\
\hline $192 \mathrm{M}$ & 28.1 & 25.0 \\
\hline 23144 & 27.0 & 23.9 \\
\hline Wales & 31.0 & 28.1 \\
\hline WUF 1 & $29.0^{\mathrm{b}}$ & $26.4^{\mathrm{b}}$ \\
\hline \multicolumn{3}{|l|}{ G. graminis var. tritici } \\
\hline 43 & ND & 25.5 \\
\hline 10 & ND & 25.6 \\
\hline 89 & ND & 27.6 \\
\hline 800 & ND & 27.8 \\
\hline 17916 & ND & 24.1 \\
\hline 23580 & $29.2^{\mathrm{b}}$ & $26.6^{\mathrm{b}}$ \\
\hline 51463 & 39.6 & 24.0 \\
\hline $\mathrm{C} 3$ & 38.4 & 30.0 \\
\hline Denmark & 38.9 & 25.4 \\
\hline Ireland & 38.9 & 32.5 \\
\hline Mexico 115 & ND & 23.0 \\
\hline Mexico 116 & 36.3 & 26.1 \\
\hline \multicolumn{3}{|l|}{ G. graminis var. graminis } \\
\hline 24167 & 39.2 & 36.8 \\
\hline 33669 & 37.3 & 38.1 \\
\hline Acc OSI & ND & ND \\
\hline ADI & ND & 37.7 \\
\hline \multicolumn{3}{|l|}{ Undescribed genus $^{\mathrm{c}}$} \\
\hline TS 53 & ND & ND \\
\hline TS 76 & ND & ND \\
\hline TS 82 & ND & ND \\
\hline TS 108 & ND & ND \\
\hline TS 128 & ND & ND \\
\hline TS 131 & ND & ND \\
\hline Phialophora sp. 219 & 38.6 & $32.8^{\mathrm{d}}$ \\
\hline Phialophora graminicola & 39.7 & $31.9^{\mathrm{e}}$ \\
\hline P. graminicola 228 & ND & 34.6 \\
\hline P. graminicola 229 & 39.1 & $31.6^{\mathrm{d}}$ \\
\hline
\end{tabular}

${ }^{a}$ Cycle threshold $(\mathrm{Ct})$ is the number of PCR cycles required for the amplified product to cross the threshold. ND = not detected.

${ }^{\mathrm{b}}$ PCR product sequenced as $G$. graminis var. avenae.

${ }^{\mathrm{c}}$ Undescribed ectotrophic root infecting fungi from golf turf hybrid couch in Queensland.

${ }^{d}$ PCR product sequenced as G. graminis var. tritici.

${ }^{\text {e }}$ PCR product sequence failed.

Table 1. Primers and probe sequences for real-time polymerase chain reaction assays for Gaeumannomyces graminis var. avenae and the combined G. graminis var. tritici plus avenae (tritici/avenae)

\begin{tabular}{lll}
\hline Target & \multicolumn{1}{c}{ tritici/avenae } & G. graminis var. avenae \\
\hline Forward primer & AACTCCAACCCCTGTGACCA & GCTTCGGCGGACGATTGT \\
Reverse primer & CGCTGCGTTCTTCATCGATGCC & TTGAAAGTTTTAATTATTTGGTTTTGTA \\
Probe & 6FAM TCGTCCGCCGAAGCA MGBNFQ & 6FAM CCGCCGGAGGTTACAA MGBNFQ \\
\hline
\end{tabular}


inoculum quantification. The roots of each plant were washed and assessed for take-all. Each plant was assessed on a scale of 0 to 4 $(0=$ no take-all and $1=1$ to $10,2=11$ to $30 ; 3=31$ to 60 , and $4=$ 61 to $100 \%$ of the root system affected). The proportion of plants in each category was used to derive a take-all index (TAI). This was calculated as TAI $=(0 a+10 b+30 c+60 d+100 c) / T$, where $a$, $\mathrm{b}, \mathrm{c}, \mathrm{d}$, and $\mathrm{e}$ are the number of plants in each of the infection categories and $\mathrm{T}=$ total number of plants $(\mathrm{a}+\mathrm{b}+\mathrm{c}+\mathrm{d}+\mathrm{e})$. The TAI has a maximum value of 100 . The incidence of take-all infection was calculated as the percentage of plants symptomatic of take-all in each sample.

Data analysis. Additional research (S. L. Bithell and M. G. Cromey, unpublished data) showed that visible aboveground takeall symptoms in crops can usually be seen when TAI exceeds 30, whereas a TAI of over 50 usually resulted in moderate to severe aboveground symptoms of take-all in a wheat crop, depending on environmental conditions during grain fill. These two disease thresholds were used to evaluate risk categories for take-all prediction. The response variables examined were proportions of fields in particular inoculum categories that exceeded a TAI of 30 (i.e., TAI 30 to 100) or 50 (i.e., TAI 50 to 100). The four risk categories-BDL, low, medium, and high (ranges of picograms of G. graminis var. tritici DNA per gram of soil; Table 3) developed by Ophel-Keller et al. (28)—were also evaluated for first, second, and third wheats separately, to determine whether the inoculum concentration/risk relationship differed according to year of wheat, and to evaluate the prediction accuracy of these risk categories.

Because preliminary analysis indicated that the potential for risk prediction is greatest for second wheats, these were selected for further analysis. To explore the relationship between soil $G$. graminis var. tritici and take-all risk, the percentage of fields with TAI exceeding 30 or 50 was plotted against soil G. graminis var. tritici concentration. However, because there was generally only one field for any given $G$. graminis var. tritici concentration which either exceeded the TAI threshold $(1 / 1$, or $100 \%)$ or did not exceed the threshold $(0 / 1$, or $0 \%)$, some smoothing of the data was required to enable the relationship to be visualized. First, the data were sorted into ascending order of G. graminis var. tritici concentration. The percentage of fields exceeding the TAI threshold (30 or 50 ) and the median G. graminis var. tritici concentration were calculated for sets of fields, with each set constituting a moving window of 10 fields across the whole G. graminis var. tritici range. The median rather than the mean $G$. graminis var. tritici concentration was chosen to reduce the influence of more extreme $G$. graminis var. tritici values. The moving window contained only one to nine values at the start and end of the smoothing process, and calculations were adjusted accordingly. Smoothing was carried

Table 3. First-, second-, and third(+)-year or later wheats in four take-all risk categories based on amounts of Gaeumannomyces graminis var. tritici DNA in soil (pg/g soil) with percentage of fields with take-all indices (TAIs) greater than 30 or 50 (2003-04, a low take-all year, and combined 2004-05 and 200506 , respectively)

\begin{tabular}{|c|c|c|c|c|c|c|}
\hline Year of wheat, category ${ }^{a}$ & $\begin{array}{l}\text { Number } \\
\text { of fields }\end{array}$ & $\begin{array}{c}\text { Mean G. graminis } \\
\text { var. tritici }\end{array}$ & $\begin{array}{c}\text { Mean } \\
\text { TAI }\end{array}$ & $\begin{array}{c}\text { TAI } \\
\text { range }\end{array}$ & $\begin{array}{c}\text { Percentage with } \\
\text { TAI > } 30 \text { (number) }\end{array}$ & $\begin{array}{c}\text { Percentage with } \\
\text { TAI }>50 \text { (number) }\end{array}$ \\
\hline \multicolumn{7}{|l|}{ First } \\
\hline \multicolumn{7}{|l|}{ 2003-04 } \\
\hline $\mathrm{BDL} \leq 5$ & 20 & 2 & 1.0 & $0-9$ & $0.0(0)$ & $0.0(0)$ \\
\hline Low $>5, \leq 130$ & 31 & 26 & 2.8 & $0-21$ & $0.0(0)$ & $0.0(0)$ \\
\hline Med $>130, \leq 325$ & 0 & $\ldots$ & $\ldots$ & $\ldots$ & $\ldots$ & $\ldots$ \\
\hline High $>325$ & 0 & $\ldots$ & $\ldots$ & $\ldots$ & $\ldots$ & \\
\hline All & 51 & 17 & 2.1 & $0-21$ & $0.0(0)$ & $0.0(0)$ \\
\hline \multicolumn{7}{|l|}{$2004-05$ and 2005-06 } \\
\hline $\mathrm{BDL} \leq 5$ & 16 & 3 & 4.9 & $0-31$ & $6.2(1)$ & $0.0(0)$ \\
\hline Low $>5, \leq 130$ & 28 & 15 & 8.4 & $0-47$ & $10.7(3)$ & $0.0(0)$ \\
\hline Med $>130, \leq 325$ & 0 & $\ldots$ & $\ldots$ & $\ldots$ & $\ldots$ & $\ldots$ \\
\hline High $>325$ & 0 & $\ldots$ & $\ldots$ & $\ldots$ & $\ldots$ & $\ldots$ \\
\hline All & 44 & 11 & 7.1 & $0-47$ & $9.1(4)$ & $0.0(0)$ \\
\hline All first wheat & 95 & 14 & 4.4 & $0-47$ & $4.2(4)$ & $0.0(0)$ \\
\hline \multicolumn{7}{|l|}{ Second } \\
\hline \multicolumn{7}{|l|}{ 2003-04 } \\
\hline $\mathrm{BDL} \leq 5$ & 4 & 3 & 7.4 & $0-18$ & $0.0(0)$ & $0.0(0)$ \\
\hline Low $>5, \leq 130$ & 12 & 31 & 17.0 & $1-64$ & $16.7(2)$ & $8.3(1)$ \\
\hline Med $>130, \leq 325$ & 2 & 246 & 33.2 & $21-45$ & $50.0(1)$ & $0.0(0)$ \\
\hline High $>325$ & 4 & 1,054 & 18.9 & $9-35$ & $25.0(1)$ & $0.0(0)$ \\
\hline All & 22 & 231 & 17.1 & $0-64$ & $18.2(4)$ & $4.5(1)$ \\
\hline \multicolumn{7}{|l|}{$2004-05$ and 2005-06 } \\
\hline $\mathrm{BDL} \leq 5$ & 20 & 2 & 7.0 & $0-51$ & $5.0(1)$ & $5.0(1)$ \\
\hline Low $>5, \leq 130$ & 46 & 42 & 38.8 & $2-85$ & $54.3(25)$ & $32.6(15)$ \\
\hline Med $>130, \leq 325$ & 17 & 210 & 60.5 & $20-93$ & $94.1(16)$ & $76.5(13)$ \\
\hline High $>325$ & 12 & 843 & 65.3 & $27-96$ & $91.7(11)$ & $75.0(9)$ \\
\hline All & 95 & 165 & 39.3 & $0-96$ & $55.8(53)$ & $40.0(38)$ \\
\hline All second wheat & 117 & 177 & 35.1 & $0-96$ & $48.7(57)$ & $33.3(39)$ \\
\hline \multicolumn{7}{|l|}{ Third+ } \\
\hline \multicolumn{7}{|l|}{ 2003-04 } \\
\hline $\mathrm{BDL} \leq 5$ & 0 & $\ldots$ & $\ldots$ & $\ldots$ & $\ldots$ & $\ldots$ \\
\hline Low $>5, \leq 130$ & 6 & 45 & 19.6 & $6-31$ & $16.7(1)$ & $0.0(0)$ \\
\hline Med $>130, \leq 325$ & 5 & 224 & 33.5 & $6-81$ & $40.0(2)$ & $20.0(1)$ \\
\hline High $>325$ & 7 & 691 & 38.8 & $10-86$ & $42.9(3)$ & $42.9(3)$ \\
\hline All & 18 & 346 & 30.9 & $6-86$ & $33.3(6)$ & $22.2(4)$ \\
\hline \multicolumn{7}{|l|}{$2004-05$ and 2005-06 } \\
\hline $\mathrm{BDL} \leq 5$ & 2 & 2 & 9.7 & $4-15$ & $0.0(0)$ & $0.0(0)$ \\
\hline Low $>5, \leq 130$ & 27 & 66 & 32.6 & $2-79$ & $55.6(15)$ & $22.2(6)$ \\
\hline Med $>130, \leq 325$ & 9 & 214 & 33.0 & $15-58$ & $44.4(4)$ & $11.1(1)$ \\
\hline High $>325$ & 11 & 538 & 32.3 & $6-91$ & $54.5(6)$ & $9.1(1)$ \\
\hline All & 49 & 197 & 31.7 & 2-91 & $51.0(25)$ & $16.3(8)$ \\
\hline All third+ wheat & 67 & 237 & 31.5 & $2-91$ & $46.3(31)$ & $17.9(12)$ \\
\hline
\end{tabular}

${ }^{\mathrm{a}}$ Risk category abbreviations: Med $=$ medium and $\mathrm{BDL}=$ below detection limit. 
out for each season separately (Fig. 1) and for combined data from the final two seasons (Fig. 2).

For prediction and comparison between seasons, it is useful to model the underlying relationship, rather than just visualizing it. Modeling was carried out using the unsmoothed data converted into a value of 1 where a field exceeded the TAI threshold (30 or 50), and a value of 0 if it did not. Therefore, the data were binomial, with the number of fields (binomial total) for each row of data being 1 , and it is appropriate to model the response using logistic regression. The following logistic response curve was fitted:

$$
\% \text { ExceedingThreshold }=\frac{C}{1+\left(\frac{G g t}{M}\right)^{-b}}
$$

Parameter $C$ is an upper asymptote for the curve. That is, it is the maximum percentage of fields exceeding the threshold over all $G$. graminis var. tritici concentrations. Parameter $M$ is the concentra- tion of $G$. graminis var. tritici where $C / 2$ fields exceed the threshold, and parameter $b$ relates to the slope of the curve at $G$. graminis var. tritici $=M$. When plotted against $\log (G$. graminis var. tritici $)$, the curve has a slope of $b C / 4$ at $G$. graminis var. tritici $=M$. The curve was fitted using a binomial generalized nonlinear modeling method (12). Comparisons between the three growing seasons were made by fitting the curve with any or all of the three parameters $(C, M$, and $b)$ allowed to vary between the seasons, comparing deviances from these models using a parallel curve fitting approach (33). The fitted relationships were used to develop an alternative $G$. graminis var. tritici risk estimation protocol. Potentially, factors such as irrigation and rainfall for individual fields could be included in the model: however, this was not done, partly because of the limited numbers of fields with each particular combination of these factors but primarily because it is useful to first explore the performance of a very simple predictive model based on only soil G. graminis var. tritici, and the usefulness of new risk categories derived from that model.
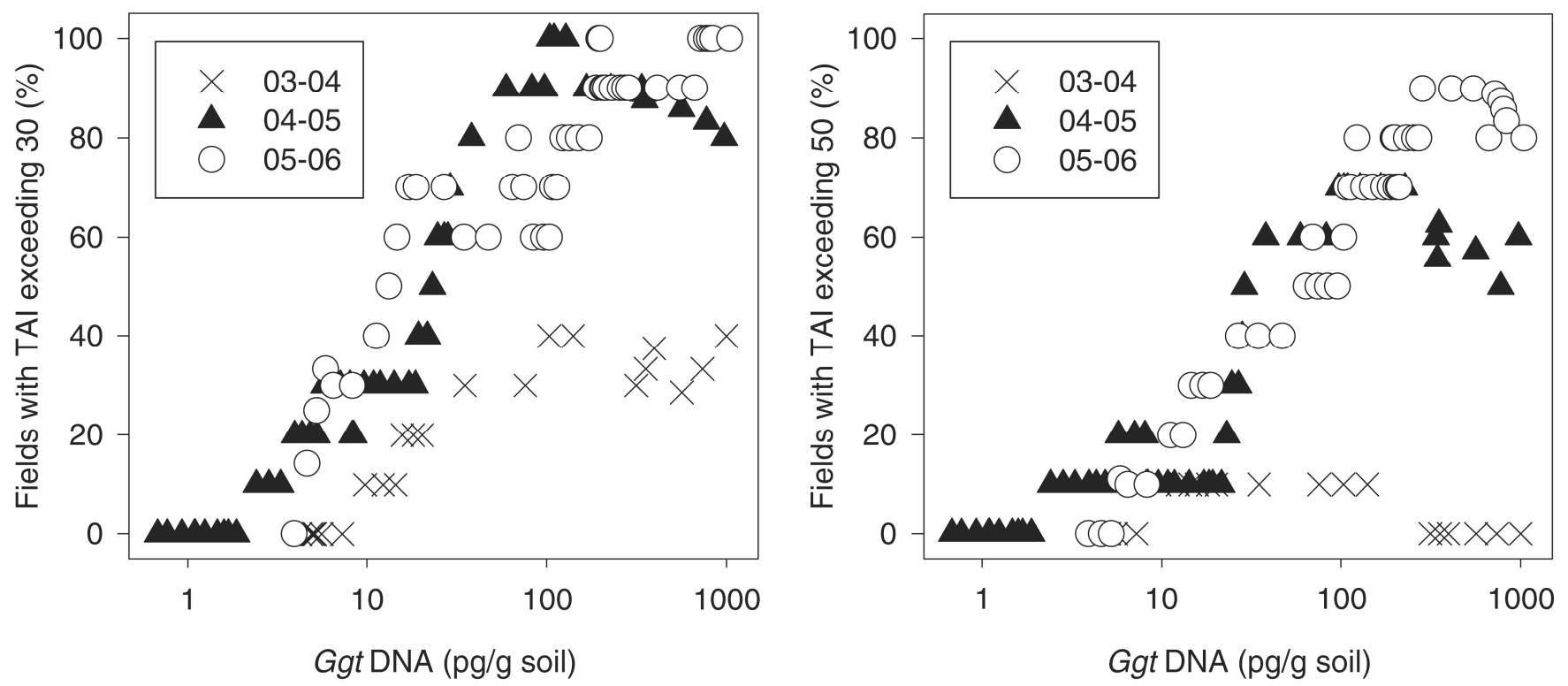

Fig. 1. Smoothed data (window of 10 running percentages) of fields with take-all indices (TAls) $>30$ (left) or $>50$ (right) against running median of Gaeumannomyces graminis var. tritici (Ggt) DNA concentrations in soil for each of three growing seasons.
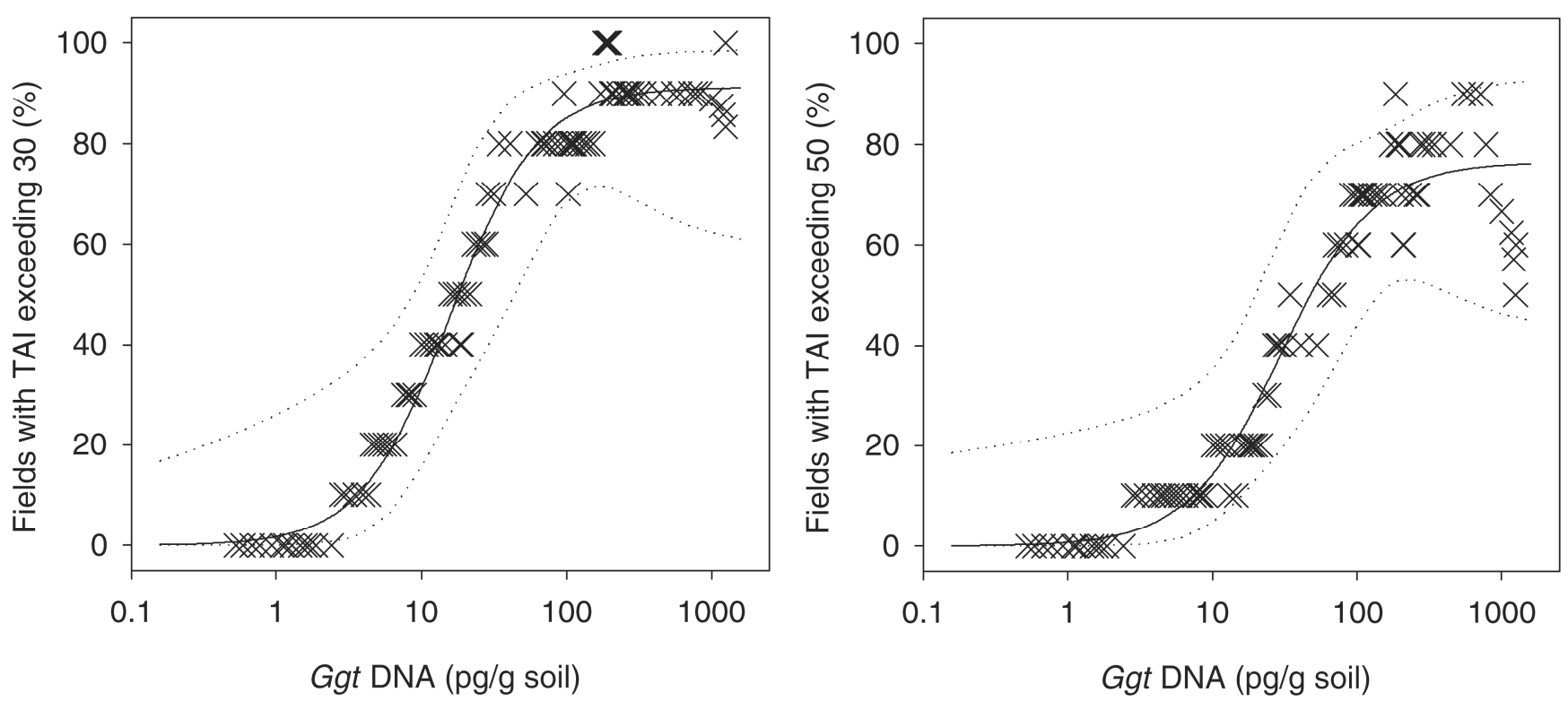

Fig. 2. Fitted response curves (solid lines) for soil concentrations of Gaeumannomyces graminis var. tritici (Ggt) (DNA at pg/g) and the percentage of fields with take-all indices (TAls) $>30$ (left) or > 50 (right) for the combined 2004-05 and 2005-06 growing seasons with $95 \%$ confidence intervals for the fitted curve (dotted lines), along with smoothed data (window of 10 , running percentages and medians). 
Commercial use of the test. New Zealand wheat growers have had access to the PCR-based take-all test since the 2007-08 growing season. Soil test and take-all data were collected in the first two growing seasons, as part of a technology transfer project. Soil samples were collected for growers by agronomists from participating grain and fertilizer companies and were processed and sent to SARDI for PCR analysis as described above. Growers were able to use the test results to aid in their sowing decisions. Sowing information was collected from growers and take-all was assessed as described above where wheat was sown.

\section{Results}

Assay specificity. The tritici/avenae assay detected high levels (low Ct values) of the G. graminis var. tritici and G. graminis var. avenae isolates and the G. graminis var. avenae assay detected all G. graminis var. avenae isolates and G. graminis var. tritici isolate 23580 but not the other $G$. graminis var. tritici isolates in the DNA collection established by Herdina et al. (16; Table 2). Nontarget species were generally not detected or gave late amplification $(\mathrm{Ct}$ values $>38$ ), which is indicative of either low-level cross-reaction or contamination. However, the Phialophora isolates were detected at $\mathrm{Ct}$ values < 35; contamination of the original DNA collection was suspected and, therefore, the PCR products of these isolates were cloned and sequenced. The PCR product of isolate 23580 was sequenced as G. graminis var. avenae and those of Phialophora sp. 219 and Phialophora graminicola 229 were sequenced as $G$. graminis var. tritici. The PCR product of $P$. graminicola could not be sequenced; this was not pursued further because the other isolates were shown to be contaminated with low levels of $G$. graminis var. tritici. Other work (5) has shown that G. graminis var. avenae is rare in New Zealand; therefore, results are described as picograms of $G$. graminis var. tritici DNA per gram of soil.

Evaluation of Australian risk categories. There were large differences between first-, second-, and third(+)-year wheat crops in the proportions of fields with TAI greater than 30 or greater than 50 in each of the risk categories (28; Table 3). All 95 first-wheat fields were in the risk categories BDL or low, only four had TAIs over 30, and none had TAIs over 50. Among the 67 third(+)-year wheat fields, only two were in the BDL category (neither of which had a TAI over 30).

There were also differences in the proportions of fields above the two severity thresholds according to year of wheat. Only $4 \%$ of first-wheat fields had a TAI over 30, compared with 49 and $46 \%$ of second- and third(+)-year wheats, respectively. The proportion of fields with a TAI over 50 peaked in second wheats (33 compared with $18 \%$ for third(+)-year wheats). For third(+)-year wheat fields, there was no discrimination between the low, medium, and high risk categories for fields with a TAI over 30 or for fields with a TAI over 50 .

Fields were separated into the 2003-04 growing season, where disease severity was relatively low (18\% of second-wheat fields had a TAI over 30) and the combined 2004-05 and 2005-06 growing seasons, where $49 \%$ of second-wheat fields had a TAI over 30 . In the latter two growing seasons, second-wheat fields formed three groups (Table 3 ). Fields in the BDL category rarely had TAIs over 30 compared with almost half the low category fields. This increased to over $90 \%$ for fields in the medium- and high-risk cate- gories. There was no evidence that fields in the high-risk category were more likely to have TAIs over 30 or over 50 than mediumrisk fields. Almost one-third of fields in the low-risk category had TAIs over 50, although this was considerably lower than for fields in the medium- to high-risk categories, where over three-quarters of fields had TAIs over 50 .

G. graminis var. tritici concentration-take-all risk relationship analysis in second-wheat fields. The results for secondwheat fields were examined in more detail to assess the current risk prediction model and develop a refined prediction protocol.

The smoothed relationship between the running percentage of fields with TAIs exceeding 30 or 50 (window of 10) plotted against a running median (window of 10) of G. graminis var. tritici is presented in Figure 1, with data for each growing season shown separately. Two features are notable. First, for the 2003-04 season, few fields had TAIs above 30 at any G. graminis var. tritici concentration, and fewer still had TAIs above 50, regardless of $G$. graminis var. tritici concentration. This contrasts strongly with the two later seasons, where more than 70 or $90 \%$ of fields had TAIs above the thresholds for moderate or high concentrations of G. graminis var. tritici. Second, for the highest concentrations of G. graminis var. tritici, there appeared to be some reduction in the percentage of fields exceeding the thresholds compared with slightly lower $G$. graminis var. tritici concentrations. This reduction was principally due to one field with higher $G$. graminis var. tritici concentrations that did not exceed the threshold. This field affected the percentages for the last few running percentages displayed. Other than these last few points, the G. graminis var. tritici concentrationtake-all risk relationship was similar for the later two seasons.

Figure 1 clearly shows that, for mid-range $G$. graminis var. tritici concentrations, the risk of take-all increases quite rapidly with increasing G. graminis var. tritici. Thus, to use boundaries for risk determination for these mid-range G. graminis var. tritici concentrations can potentially be misleading. A field with, for example, G. graminis var. tritici DNA at $20 \mathrm{pg} / \mathrm{g}$ of soil has about a $20 \%$ chance of having above $50 \%$ TAI in a take-all year, whereas one at $95 \mathrm{pg}$ has close to an $80 \%$ chance. The current Australian risk categories do not suggest such a large difference in risk for these two concentrations of $G$. graminis var. tritici. Thus, a more useful approach may be developed by modeling the take-all risk- $G$. graminis var. tritici relationship, to allow risk for the mid-range values to be estimated for individual $G$. graminis var. tritici values.

Comparison of $G$. graminis var. tritici response curves for the three seasons for thresholds of TAI of 30 or 50 using parallel curve analysis showed that the relationship for the 2003-04 season varied significantly from that for the other two seasons, with a significantly lower maximum response (asymptote, parameter $C, P<$ $0.001)$, and also significantly different $M$ parameters $(P<0.05)$. However, none of the three parameters of the curve differed significantly between the 2004-05 or 2005-06 seasons $(P>0.05)$. The logistic function did not adequately describe the relationship between $G$. graminis var. tritici concentration and the percentage of fields with TAIs greater than 50 in the 2003-04 season, because there were few fields with TAI above 50 in that season. Thus, this curve is not presented. The parameters for a curve fitted to the 2003-04 season data and a separate curve fitted to the combined data for the 2004-05 and 2005-06 seasons are shown in Table 4

Table 4. Parameters of fitted response curves $(C, b$, and $M)$ and derived parameters for Gaeumannomyces graminis var. tritici DNA concentrations (pg/g of soil) and the percentage of fields with take-all indices (TAIs) $>30$ or $>50$ from the 2003-04 growing season or the 2004-05 and 2005-06 growing seasons combined, respectively ${ }^{\mathrm{a}}$

\begin{tabular}{|c|c|c|c|}
\hline \multirow[b]{2}{*}{ Parameter } & \multirow{2}{*}{$\begin{array}{c}2003-04 \\
\text { TAI }>30\end{array}$} & \multicolumn{2}{|c|}{ 2004-05 2005-06 combined } \\
\hline & & TAI $>30$ & $\mathbf{T A I}>\mathbf{5 0}$ \\
\hline$C$ (percent fields) & $36.5(23.0)$ & $91.2(8.0)$ & $76.6(13.5)$ \\
\hline$b\left(\log \mathrm{pg}\right.$ of G. graminis var. tritici $\left.{ }^{-1}\right)$ & $3.5(2.5)$ & $3.3(1.4)$ & $3.1(1.5)$ \\
\hline$M(\mathrm{pg}$ of DNA) & $23.9(40.9)$ & $15.8(6.3)$ & $29.9(18.6)$ \\
\hline Percentage at $G$. graminis var. tritici $=M$ (percent fields) & $18.2(11.5)$ & $45.6(4.0)$ & $38.3(6.8)$ \\
\hline Slope at $G$. graminis var. tritici $=M($ percent fields $/ \log$ pg of $G$. graminis var. tritici $)$ & $32.3(21.1)$ & $74.9(27.8)$ & $59.7(23.0)$ \\
\hline
\end{tabular}

a Numbers in parentheses are standard errors for the estimated parameters. 
and the curves are illustrated in Figure 2. The confidence intervals given in this figure illustrate the precision of the fitted curve, rather than the likely range of future values for new fields. Confidence intervals for predicted risk are larger. For the TAI 30 threshold, the lower overall take-all severity in the 2003-04 season resulted in a lower upper asymptote value (36.5\% of fields for the highest $G$. graminis var. tritici concentrations resulting in TAI above 30) than for the following two take-all conducive seasons, where $91.2 \%$ of fields with high $G$. graminis var. tritici resulted in TAI above 30. The high incidence of severe take-all in the later two seasons was also demonstrated by the upper asymptote for fields with TAIs greater than $50(76.6 \%)$ being greater than the upper asymptote for fields with TAIs greater than 30 in the 2003-04 season.

The initial assessment of the raw data suggested that the Australian categories are inadequate for risk prediction for the mid-range G. graminis var. tritici concentrations. The model suggests a threepart strategy: low to negligible risk for the lowest G. graminis var. tritici concentrations, high risk for the highest $G$. graminis var. tritici concentrations, and an intermediate range where risk increases rapidly with increasing $G$. graminis var. tritici. Natural cutoff points between low to negligible risk, the rapidly increasing fairly linear midsection of the relationship, and the high-risk section are the two "shoulder" points of the curve, where the shape of the curve is changing most rapidly. These shoulder points can be calculated from the parameters of the curves and are shown in Table 5. Taking the results for all three curves together suggests that values of $G$. graminis var. tritici $\leq 6$ consistently have a low to negligible risk of damaging take-all. Similarly, G. graminis var. tritici values $>80$ were consistently associated with a high risk of take-all.

Evaluation of alternative risk-prediction systems. The modeled G. graminis var. tritici-take-all risk relationship was used to develop alternative risk categories or risk-evaluation methods. The shoulder points (Table 5) enabled two logical boundaries (a low and a high one) to be chosen, resulting in three risk categories (Table 6). For values of $G$. graminis var. tritici of $6 \mathrm{pg} / \mathrm{g}$ or below, the risk is negligible to low while, for $G$. graminis var. tritici values above $80 \mathrm{pg} / \mathrm{g}$, the risk is high in a take-all year. Across all years, 26 and $40 \%$ of fields fell into the low- and high-risk categories, respectively. The intermediate-risk category $(G$. graminis var. tritici DNA at 6 to $80 \mathrm{pg} / \mathrm{g}$ of soil) comprised $34 \%$ of fields, where risk rises rapidly with increasing $G$. graminis var. tritici concentrations.

For intermediate values, risk can be individually estimated, either from the equations for the curve (Table 5, and formula in Materials and Methods), or from a graph, as in the example below (Fig. 3).

For an estimated soil G. graminis var. tritici concentration of 20 $\mathrm{pg} / \mathrm{g}$, the risk of TAI $>30$ is moderate to low in a growing season

Table 5. Lower and upper shoulder points of the three fitted curves: picograms of Gaeumannomyces graminis var. tritici DNA per gram of soil

\begin{tabular}{lccc}
\hline Growing season & TAI $(\%)$ & Lower & Upper \\
\hline 2003-04 & $>30$ & 10.2 & 56.3 \\
2004-05 and 2005-06 & $>30$ & 6.3 & 39.6 \\
& $>50$ & 11.3 & 79.0 \\
\hline
\end{tabular}

that is not a take-all year. However, in a take-all year, the risk of TAI $>30$ is high, and the risk of severe take-all ( $>50$ TAI) is moderate. For an estimated soil G. graminis var. tritici concentration of $50 \mathrm{pg} / \mathrm{g}$, the risk of TAI $>30$ is moderate when not a takeall year but very high in a take-all year, and the risk of severe takeall is also high.

Commercial validation of prediction. These data were collected in the 2007-08 and 2008-09 growing seasons (data combined) and are for second wheats only (Table 7). Presowing soil test results were categorized using the alternative New Zealand categories presented in Table 6. Some growers chose not to sow wheat but the soil test results do not appear to have strongly affected this decision in these first 2 years of commercial use of the test, because similar percentages were sown for each category. In fact, a crop was sown in the field that had the highest $G$. graminis var. tritici concentration of $2,738 \mathrm{pg} / \mathrm{g}$ of soil. Take-all incidence in this field was $82 \%$ plants infected, although the TAI was only 17 , suggesting that inoculum was distributed quite evenly across the field. Whereas primary infection was widespread, secondary infection was more limited, leading to a relatively low overall takeall severity.

Although crop choice was not strongly affected, sowing dates tended to differ between the risk categories. The median sowing date for fields in the low, intermediate, and high categories were 21 April, 10 April, and 14 May, respectively, indicating that, where growers chose to sow into high-risk fields, they usually sowed them later than fields in the lower risk categories.

The predicted percentage of fields with a TAI $>30 \%$, using the 2003-04 prediction curve (developed for a growing season that is not a take-all year) was reasonably similar to the actual percentage of fields, albeit with slightly higher actual than predicted percentages for the lower categories and a lower actual than predicted percentage for the high-risk category (Table 7). Only 3 of 72 fields sown (4\%) had TAI greater than 50, compared with $80 \%$ for 2004 06 and $5 \%$ in 2003-04; thus, these were generally moderate TAI years. However, one of the fields with TAI $>50$ had a presowing inoculum result of $G$. graminis var. tritici DNA at $<6 \mathrm{pg} / \mathrm{g}$ soil. This may be due to sampling problems.

\section{Discussion}

Prediction systems for plant diseases are most often used to predict whether the disease will exceed an incidence or severity threshold where crop protection measures, such as fungicide applications, will be justified $(26,39)$. In the case of take-all, where control options after sowing are limited, the only realistic crop protection measures are whether, what, and when to sow. Results of the present study provide evidence that the risk of take-all in wheat crops can be predicted by measuring presowing inoculum concentrations of the pathogen. Risk prediction is influenced, however, by factors such as numbers of years planted to wheat and differences between growing seasons.

Soil bioassays have been used in the United Kingdom as the major factor in deciding which fields were unsafe for cereals but the methods proved unreliable and their use for advisory purposes was discontinued by the end of the 1960s (20). More recently, Herdina et al. (18) and Herdina and Roget (17) used the correlation of a DNA-based assay of $G$. graminis var. tritici and a soil bioassay

Table 6. Alternative risk categories derived from logistic modeling

\begin{tabular}{|c|c|c|c|c|c|c|}
\hline Growing season, risk category & $\begin{array}{c}\text { Number of } \\
\text { fields }\end{array}$ & $\begin{array}{c}\text { Mean G. graminis } \\
\text { var. tritici }\end{array}$ & $\begin{array}{c}\text { Mean } \\
\text { TAI }\end{array}$ & $\begin{array}{c}\text { TAI } \\
\text { range }\end{array}$ & $\begin{array}{c}\text { Percentage with } \\
\text { TAI > } 30 \text { (number) }\end{array}$ & $\begin{array}{c}\text { Percentage with } \\
\text { TAI }>50 \text { (number) }\end{array}$ \\
\hline \multicolumn{7}{|l|}{ 2003-04 } \\
\hline Low $\leq 6$ & 6 & 4 & 7.1 & $0-18$ & $0.0(0)$ & $0.0(0)$ \\
\hline Intermediate $>6, \leq 80$ & 8 & 19 & 16.6 & $1-64$ & $12.5(1)$ & $12.5(1)$ \\
\hline High $>80$ & 8 & 614 & 25.0 & $9-49$ & $37.5(3)$ & $0.0(0)$ \\
\hline \multicolumn{7}{|l|}{$2004-05$ and 2005-06 } \\
\hline Low $\leq 6$ & 24 & 3 & 8.2 & $0-51$ & $8.3(2)$ & $4.2(1)$ \\
\hline Intermediate $>6, \leq 80$ & 32 & 27 & 37.2 & $8-85$ & $50.0(16)$ & $25.0(8)$ \\
\hline High $>80$ & 39 & 378 & 60.2 & $20-96$ & $89.7(35)$ & $74.4(29)$ \\
\hline
\end{tabular}


using field soils from various sites in Australia to develop take-all risk boundaries. Correlations were highest where soils types were similar. The present study used a comparison of presowing $G$. graminis var. tritici concentrations with subsequent take-all in wheat crops to evaluate the Australian risk boundaries.

Crop rotation has traditionally provided effective control of takeall; therefore, it is not surprising that soilborne G. graminis var. tritici concentrations and disease severity in first wheats in our study were almost always low. Although $G$. graminis var. tritici inoculum can persist for long periods in cereal crop residues, the bulk of these residues will not persist during a break crop in environments with adequate soil moisture and microbial activity $(10,24)$. Break crops have been demonstrated to minimize carryover of G. graminis var. tritici $(19,29)$. In our study, only $4 \%$ of first wheat crops had a TAI over 30 and none were over 50, indicating that the risk in first wheats is too low for prediction to offer any added benefits.

Take-all risk was not well predicted in third(+)-year wheats. Only $3 \%$ of these fields were in the lowest risk category, while there was little differentiation among the fields where G. graminis var. tritici was detected ( $>5 \mathrm{pg} / \mathrm{g}$ soil). It is also of note that third(+)-year wheats in fields with $G$. graminis var. tritici concentrations $>130 \mathrm{pg}$ had less take-all than second wheats with similar G. graminis var. tritici concentrations, suggesting the presence of take-all suppression. Other research has identified that take-all suppression can be initiated in second wheats and is evident in third wheats following take-all years $(3,37)$. Take-all suppression has been identified in New Zealand (6) and, therefore, may limit the predictive ability of presowing $G$. graminis var. tritici concentrations in third and subsequent wheat crops.

Prediction of take-all risk has the most potential in second-wheat crops, where the greatest variation in disease occurs and the inoculum-risk relationship is strongest. The inoculum-risk categories used in Australia (28) proved useful to separate fields broadly according to the risk of visible (TAI $>30$ ) or moderate to severe (TAI $>50$ ) take-all. In all, $70 \%$ of second-wheat fields were in the two lowest risk categories, where severe take-all seldom occurred. Use of the test to avoid the $30 \%$ of fields at most risk of take-all would reduce growers' losses from the disease. The Australian risk categories gave best differentiation between fields with little risk of take-all (soils with $G$. graminis var. tritici concentrations below detection) and those with some risk of take-all (soils with detect-
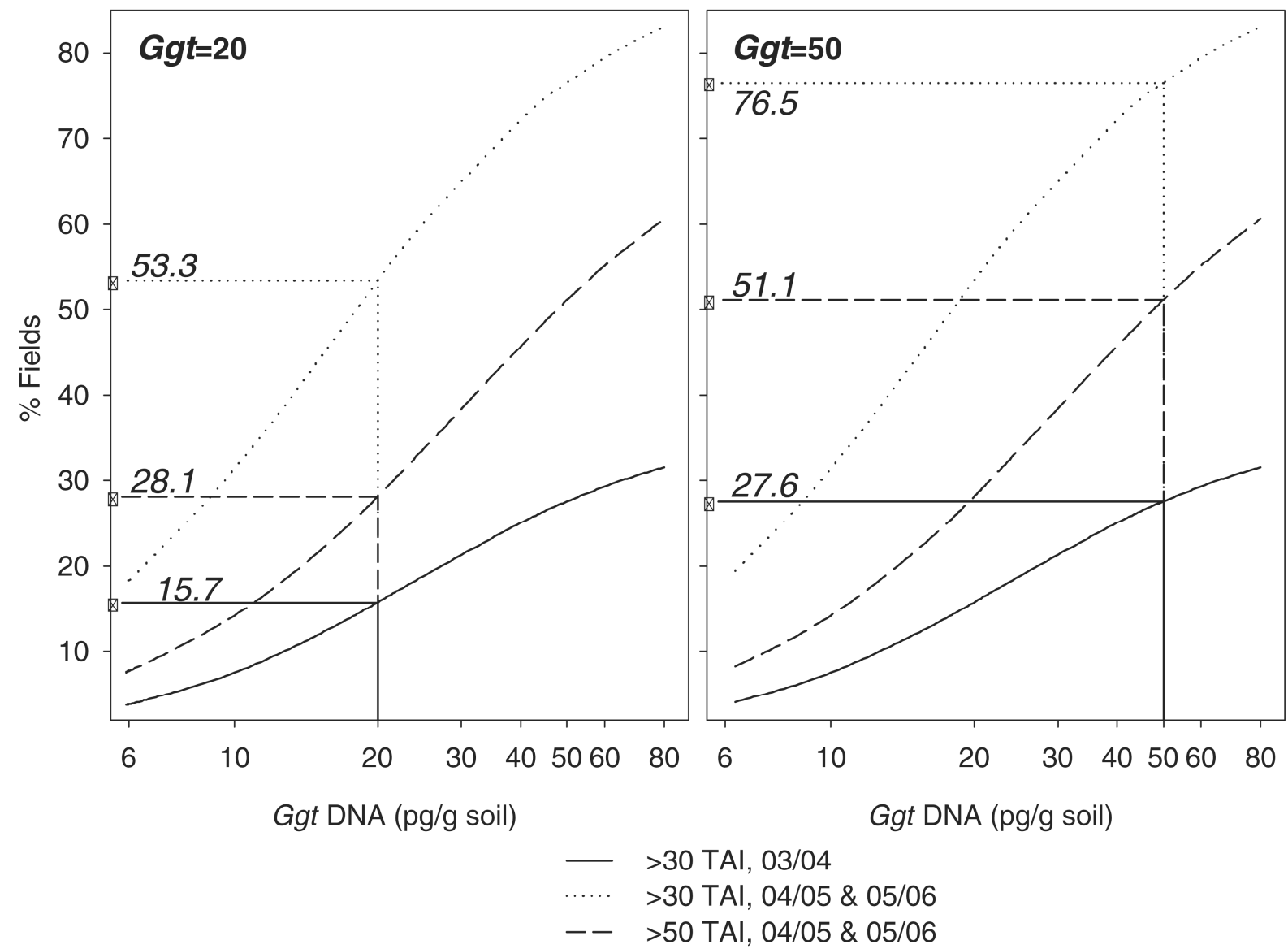

Fig. 3. Predicted percentage of fields exceeding a take-all index (TAl) of 30 or 50 for two soil Gaeumannomyces graminis var. tritici (Ggt) concentrations in a low take-all season (2003-04) or a high take-all season (2004-05 and 2005-06). Numbers in italics show the predicted percentage of fields for two selected levels of measured G. graminis var. tritici (20 or 50 ) for the two models for $>30 \%$ TAl and the model for $>50 \%$ TAl.

Table 7. Numbers of commercial fields tested and sown in wheat and take-all parameters (mean and range in take-all index [TAI], predicted [based on 200304 data], and actual percentage of fields with TAI > 30) in the 2007-08 and 2008-09 growing seasons

\begin{tabular}{|c|c|c|c|c|c|c|}
\hline \multirow[b]{2}{*}{ Category $^{\mathbf{a}}$} & \multirow[b]{2}{*}{ Number of fields } & \multirow[b]{2}{*}{ Fields sown $(\%)$} & \multicolumn{2}{|c|}{ Take-all index (TAI) } & \multicolumn{2}{|c|}{ Percent sown fields with TAI $>30$ (number) } \\
\hline & & & Mean & Range & Actual & Predicted \\
\hline $\mathrm{BDL} \leq 6$ & 33 & $24(73)$ & 10.9 & $0-74$ & $8.3(2)$ & $0.0(0)$ \\
\hline Int $>6, \leq 79$ & 24 & $17(71)$ & 23.0 & $0-77$ & $29.4(5)$ & $20.1(3)$ \\
\hline High $>79$ & 44 & $31(70)$ & 20.9 & $1-49$ & $25.8(8)$ & 36.4 (11) \\
\hline
\end{tabular}

${ }^{\text {a }}$ Risk category abbreviations: Int $=$ intermediate and $\mathrm{BDL}=$ below detection limit. 
able G. graminis var. tritici). The low-risk category was also useful, with less than half the risk of severe take-all compared with fields in the medium- and high-risk categories.

Differentiation of the risk between second wheats in the medium- and high-risk categories was difficult. This suggested that, once a certain concentration of inoculum is reached, either there is no quantitative relationship between $G$. graminis var. tritici and take-all risk, the G. graminis var. tritici boundary concentrations were inappropriately positioned, or a combination of these two possibilities applied. Therefore, the relationship between $G$. graminis var. tritici and take-all risk was examined in more detail.

The reliability of a risk warning is important and can be considered in terms of "false positives" and "false negatives". When predicting that the risk is low, there will be the expectation by growers that severe take-all will not occur. However, a minority (as expected in the model) where the unexpected happens tend to dominate perceptions of test reliability, thereby introducing a perceived bias toward failure (20). Conversely, a high risk does not guarantee that take-all will occur (even for the highest levels of G. graminis var. tritici, risk of severe infection will always be below 100\%; Fig. 2) but farmers are less likely to interpret a lack of take-all when there was a high risk prediction as a failure of the test.

There were large differences between growing seasons in the relationships between inoculum and take-all risk. Conditions in the 2003-04 season were less favorable (there was relatively low rainfall throughout the growing season) for the development of severe take-all than the two later seasons, having much lower take-all at the same concentrations of inoculum. The greater range of take-all severity for the two take-all years (growing seasons when take-all symptoms are widespread; 21) provided more separation between fields with low and high severity. Separation between risk categories will be most important in take-all years, because it is during these seasons that yield losses due to take-all are greatest (13).

Plots of smoothed data (Fig. 1) showed that the G. graminis var. tritici-take-all risk relationship was sigmoidal. Previous studies have explored the relationship between $G$. graminis var. tritici concentration and take-all severity, finding it to be linear (17) or nonlinear $(18,25)$. However, those findings cannot be directly converted into estimates of risk. The fields used in the present study possibly provided a wider range of $G$. graminis var. tritici concentrations than in previous studies $(17,18,25)$. Maximum concentrations were at least 10 times greater than those of sites in South Australia reported to have high G. graminis var. tritici concentrations, though these Australian concentrations were measured using a different molecular technique (17). There are also differences in wheat plant density, crop duration, rainfall, soil fertility, and irrigation availability between these regions $(8,23)$. Our results indicate that New Zealand cropping practices and environmental conditions can be favorable for the development of high inoculum concentrations (5).

The logistic curve potentially provides the ability to predict takeall risk, thus allowing the degree of take-all risk to be estimated for any G. graminis var. tritici concentration. Actual take-all severity in crops can vary considerably, even for the highest and lowest concentrations of G. graminis var. tritici. This variation is, in part, because of variation in the timing and severity of epidemics, which is an acknowledged characteristic of take-all (37). The observed variability in actual take-all severity probably represents the natural range under commercial cropping conditions and affects the ability to predict take-all in individual fields.

The model provided a method to identify an improved take-all risk assessment protocol. Because the relationship between $G$. graminis var. tritici inoculum and the proportion of fields exceeding a particular TAI is sigmoidal, risk for the rapidly rising midsection of the curve cannot easily be categorized. Therefore, we have proposed a three-part protocol, with low risk when G. graminis var. tritici $\leq 6$, moderate or high risk when $G$. graminis var. tritici $>80$, and graphical or equation-based methods for assessing risk between these boundaries. Although risk when G. graminis var. tritici $\leq 6$ was low for all seasons studied, for the high G. graminis var. tritici $>80$ category, actual risk was affected by whether the season was a take-all year or not. For intermediate values, cautious farmers may base their decisions on the estimated risk of TAI $>50$ for the combined 2004-05 2005-06 curve, whereas less risk-averse farmers may base their decision on the estimated risk of TAI $>30$ from the curve for the 2003-04 season, which was not a take-all year. Future improvements in long-term weather forecasting may enable growers to incorporate the likelihood of a take-all year into their sowing decisions.

Soilborne inoculum concentrations above which significant reductions in yield occur, or at which the risk of disease is greater than a particular disease incidence or severity, have been identified for some diseases $(15,27)$. For instance, analyses of the disease incidence-inoculum relationship for Verticillium dahliae have been used to identify a single inoculum concentration boundary, above which the risk of Verticillium wilt is significant $(4,38)$. Twengstrom et al. (35), using a risk point model (based on six factors) to forecast Sclerotinia stem rot in oilseed rape, chose two values for spraying recommendations. Fields with risk points above the upper value were recommended for spraying and fields with risk points below the lower value were not recommended for spraying. Disease severity was usually moderate in the intermediate interval where the value of spraying is less clear-cut.

The use of two risk boundaries (giving three risk categories) is justified for predicting the risk of take-all, taking into account the lack of accurate long-term weather forecasts. Three categories are of value for management of take-all; for example, autumn sowing could be delayed in fields with intermediate risk, while high-risk fields could be sown in spring or sown to a nonhost crop $(7,14)$. For instance, Bithell et al. (5) found that, in New Zealand, soil inoculum concentrations declined by an average of $78 \%$ in the 5 months following harvest (late summer to winter). The use of risk curves, especially for intermediate risk, allows for flexibility on the part of the grower (39). A risk-averse decision maker may set the criteria level in a different part of the curve from a decision maker willing to take a greater risk.

Local knowledge can be used by growers to combine with soil test results. For instance, different soil types (21) and management factors (22) have been shown to be associated with higher or lower risk of take-all. Although data on the effects of different soil types on take-all risk in New Zealand are not available, individual growers often have built up local knowledge of particular fields that are more or less prone to take-all problems than others.

Analysis of the first 2 years in which the soil test was used commercially in New Zealand gives some insight into how the test might be used, and the degree of risk aversion of New Zealand wheat growers. Two features stand out when examining the data. First, a similar proportion of fields in each of the three risk categories was sown in wheat (around $70 \%$ ). Second, fields in the highest risk category were sown later than those in the lower categories. This suggests that growers were not particularly risk averse and set their risk tolerance somewhere between that of 2003-04 (where take-all was seldom severe) and the take-all years of 2004-05 and 2005-06. It is also possible that many growers will not fully utilize a predictive test until it has been shown to be useful by leading farmers. The prevailing high value of wheat in comparison with other arable cropping options was likely to have resulted in a relatively low risk aversion among growers. It is also probable that growers will self-monitor their decisions over the first years of using a predictive test, and adjust their risk tolerance over time. The decision to sow higher-risk fields later will have reduced likelihood of take-all, given that soilborne inoculum concentrations have been shown to drop rapidly in the months following harvest (5). Smiley (34) also found that take-all severity was greatest in early-sown wheat while Colbach et al. (7) found that delayed planting reduced severity in the primary infection cycle during the early stages of the epidemic.

In conclusion, the wide range of G. graminis var. tritici concentrations and relatively large number of sites across three growing seasons included in this study provide a strong basis to evaluate the 
G. graminis var. tritici-take-all risk relationship. An analysis of the relationship between inoculum concentration and proportion of commercial fields exceeding particular TAI thresholds has not previously been carried out for this pathogen. The two take-all years provided an opportunity to identify soilborne inoculum categories for disease prediction on a risk-averse basis, given that prediction of growing-season climate prior to sowing is difficult. This work has demonstrated that there is statistical justification for the use of three categories, based on $G$. graminis var. tritici concentrations detected by quantitative DNA assays in soil, to predict the risk of take-all prior to sowing a second-wheat crop.

\section{Acknowledgments}

This research was funded by a New Zealand Foundation for Research Science and Technology contract (LINX0304), the MAF Sustainable Farming Fund, and the New Zealand Foundation for Arable Research. We thank the numerous farmers who gave access to their fields for this study; and I. Dumitrescu, R. Burns, and A. Thomson for processing the soil samples.

\section{Literature Cited}

1. Asher, M. J. C., and Shipton, P. J., eds. 1981. Biology and Control of TakeAll. Academic Press Inc., Ltd., London.

2. Bateman, G. L., Gutteridge, R. J., and Jenkyn, J. F. 2004. Take-all and grain yields in sequences of winter wheat crops testing fluquinconazole seed treatment applied in different combinations of years. Ann. Appl. Biol. 145:317-330.

3. Bateman, G. L., and Hornby, D. 1999. Comparison of natural and artificial epidemics of take-all in sequences of winter wheat crops. Ann. Appl. Biol. 135:555-571

4. Berbegal, M., Ortega, A., Garcia-Jimenez, J., and Armengol, J. 2007. Inoculum density-disease development relationship in Verticillium wilt of artichoke caused by Verticillium dahliae. Plant Dis. 91:1131-1136.

5. Bithell, S. L., McLachlan, A. R. G., Hide, C. C. L., McKay, A., and Cromey, M. G. 2009. Changes in post-harvest levels of Gaeumannomyces graminis var. tritici inoculum in wheat fields Australas. Plant Pathol. 38:277-283.

6. Chng, S. F. 2009. Microbial factors associated with the natural suppression of take-all in wheat in New Zealand. Ph.D. thesis, Lincoln University, Lincoln, New Zealand.

7. Colbach, N., Lucas, P., and Meynard, J. M. 1997. Influence of crop management on take-all development and disease cycles on winter wheat. Phytopathology 87:26-32.

8. Cotterill, P. J., and Sivasithamparam, K. 1989. An autecological study of the take-all fungus (Gaeumannomyces graminis var. tritici) in Western Australia. Aust. J. Agric. Res. 40:229-240.

9. Cromey, M. G., Parkes, R. A., and Fraser, P. M. 2006. Factors associated with stem base and root diseases of New Zealand wheat and barley crops. Australas. Plant Pathol. 35:1-10.

10. Curtin, D., Francis, G. S., and McCallum, F. M. 2008. Decomposition rate of cereal straw as affected by soil placement. Aust. J. Soil Res. 46:152-160.

11. De Wolf, E. D., and Isard, S. A. 2007. Disease cycle approach to plant disease prediction. Annu. Rev. Phytopathol. 45:203-220.

12. GenStat Committee. 2008. The Guide to GenStat Release 11-Part 2: Statistics. VSN International, Oxford.

13. Gutteridge, R. J., Bateman, G. L., and Todd. A. D. 2003. Variation in the effects of take-all disease on grain yield and quality of winter cereals in field experiments. Pest Manage. Sci. 59:215-224.

14. Gutteridge, R. J., and Hornby, D. 2003. Effects of sowing date and volunteers on the infectivity of soil infested with Gaeumannomyces graminis var. tritici and on take-all disease in successive crops of winter wheat.
Ann. Appl. Biol. 143:275-282.

15. Harris, D. C., and Yang, J. R. 1996. The relationship between the amount of Verticillium dahliae in soil and the incidence of strawberry wilt as a basis for disease risk prediction. Plant Pathol. 45:106-114.

16. Herdina, Harvey, H. P., and Ophel-Keller, K. 1996. Quantification of Gaeumannomyces graminis var. tritici in infected roots and soil using slot-blot hybridization. Mycol. Res. 100:962-970.

17. Herdina, and Roget, D. K. 2000. Prediction of take-all disease risk in field soils using a rapid and quantitative DNA soil assay. Plant Soil 227:87-98.

18. Herdina, Yang, H. A., and Ophel-Keller, K. 1997. Correlation of take-all disease severity and inoculum level of Gaeumannomyces graminis var. tritici using a slot-blot hybridization assay. Mycol. Res. 101:1311-1317.

19. Hornby, D. 1975. Inoculum of the take-all fungus: nature, measurement, distribution and survival. EPPO Bull. 5:319-333.

20. Hornby, D. 1978. The problem of trying to forecast take-all. In: Plant Disease Epidemiology. P. R. Scott and A. Bainbridge, eds. Blackwell Scientific Publications, Oxford.

21. Hornby, D. 1998. Take-All Disease of Cereals: A Regional Perspective. CAB International, Wallingford UK.

22. Huber, D. M., and McCay-Buis, T. S. 1993. A multiple component analysis of the take-all disease of cereals. Plant Dis. 77:437-447.

23. Jamieson, P. D., Porter J. R., and Wilson, D. R. 1991. A test of the computer simulation model ARCWHEAT1 on wheat crops grown in New Zealand. Field Crops Res. 27:337-350.

24. MacNish, G. C. 1973. Survival of Gaeumannomyces graminis var. tritici in field soil stored in controlled environments. Aust. J. Biol. Sci. 26:13191325 .

25. MacNish, G. C., Liddle, J. M., and Powelson, R. L. 1986. Studies on the use of high- and low-nutrient inoculum for infection of wheat by Gaeumannomyces graminis var. tritici. Phytopathology 76:815-819.

26. Madden, L. V. 2006. Botanical epidemiology: some key advances and its continuing role in disease management. Eur. J. Plant Pathol. 115:3-23.

27. Nnodu, E. C., and Harrison, M. D. 1979. The relationship between Verticillium albo-atrum inoculum density and potato yield. Am. Potato J. 56:11-25.

28. Ophel-Keller, K., McKay, A., Hartley, D., Herdina, and Curran, J. 2008. Development of a routine DNA-based testing service for soilborne diseases in Australia. Australas. Plant Pathol. 37:243-253.

29. Polley, R. W., and Thomas, M. R. 1991. Surveys of diseases of winter wheat in England and Wales, 1976-1988. Ann. Appl. Biol. 119:1-20.

30. Riley, I. T., Wiebkin, S., Hartley, D., and McKay, A. C. 2009. Quantification of roots and seeds in soil with real-time PCR. Plant Soil 331:151-163.

31. Roget, D. K. 2001. Prediction modelling of soilborne plant diseases. Australas. Plant Pathol. 30:85-89.

32. Roget, D. K., and Rovira, A. D. 1991. The relationship between incidence of infection by the take-all fungus (Gaeumannomyces graminis var. tritici), rainfall and yield of wheat in South Australia. Aust. J. Exp. Agric. 31:509513.

33. Ross, G. J. S. 1990. Nonlinear Estimation. Springer-Verlag, New York.

34. Smiley, R. W. 2009. Water and temperature parameters associated with winter wheat diseases caused by soilborne pathogens. Plant Dis. 93:73-80.

35. Twengstom, E., Sigvald, R., Svensson, C., and Yuen, J. 1998. Forecasting Sclerotinia stem rot in spring sown oilseed rape. Crop Prot. 17:405-411.

36. Werker, A. R., and Gilligan, C. A. 1990. Analysis of the effects of selected agronomic factors on the dynamics of the take-all disease of wheat in field plots. Plant Pathol. 39:161-177.

37. Werker, A. R., Gilligan, C. A., and Hornby, D. 1991. Analysis of diseaseprogress curves for take-all in consecutive crops of winter wheat. Plant Pathol. 40:8-24.

38. Xiao, C. L., and Subbarao, K. V. 1998. Relationships between Verticillium dahliae inoculum density and wilt incidence, severity, and growth of cauliflower. Phytopathology 88:1108-1115.

39. Yuen, J. E., and Hughes, G. 2002. Bayesian analysis of plant disease prediction. Plant Pathol. 51:407-412. 